\title{
Biofilmes formados em matéria-prima em contato com leite: fatores de virulência envolvidos*
}

\author{
Biofilm formation from milk in contact with raw material: virulence factors involved \\ Juliana Flach ${ }^{1}$, Carolina Karnopp ${ }^{2}$ \& Gertrudes Corção ${ }^{1,3}$
}

\begin{abstract}
RESUMO
Biofilmes bacterianos representam uma preocupação à indústria de alimentos por sua potencialidade em resistir a tratamentos antimicrobianos, além de degradar e contaminar os alimentos com patógenos. O presente trabalho avaliou a relação entre fatores de adesão e hidrofobicidade celular na formação de biofilmes, bem como as atividades citotóxica e proteolítica de isolados bacterianos do biofilme. Corpos de prova compostos de polipropileno, aço inoxidável e pano de algodão foram imersos em leite in natura, em diferentes condições de tempo e temperatura. Posteriormente, foram lavados com solução Salina Fosfatada Tamponada e submetidos à sonicação para remoção das células aderidas. Estas foram isoladas, identificadas e submetidas aos testes de produção de cápsula, fímbria, hemolisina, protease e determinação da hidrofobicidade celular. Dos 101 isolados obtidos, 57 foram Gram negativos e 44, Gram positivos; 52,5\% foram produtores de cápsula, 49,4\% de fímbria, 4,0\% de fímbria tipo I, $53,5 \%$ de hemolisina e $20,2 \%$ de proteases. A maioria dos isolados teve hidrofobicidade celular elevada, e a associação entre presença de cápsula e adesão em pano de algodão foi estatisticamente significante. A presença de bactérias potencialmente patogênicos como Escherichia coli, Staphylococcus aureus e Staphylococcus coagulase-negativos, revela a necessidade do controle microbiológico já em nível de produção de leite, no sentido de evitar complicações à saúde pública.
\end{abstract}

Descritores: biofilmes, leite, bactérias, fatores de virulência, hidrofobicidade.

\section{ABSTRACT}

Bacterial biofilms represent a concern to food industry, once they can develop resistance to antimicrobial treatments and due to its degradation activity and food contamination with pathogens. The present study evaluated the influence of adhesion factors and cellular hydrophobicity in biofilm formation, besides the citotoxic and proteolytic activity of the strains isolated from the biofilm. Pieces of polypropylene, stainless steel and cotton cloth were used to analyse the biofilm formation; they were placed directly into raw milk samples, at different time and temperature conditions. Afterwards, the pieces were washed with Phosphate Buffered Saline and submitted to sonication, in order to remove the attached cells. These bacterial cells were isolated, identified and analysed for production of capsule, fimbriae, hemolysin and proteolytic activity, besides cellular hydrophobicity. From the 101 isolated strains, 57 were Gram-negative and 44 were Gram-positive; 52.5\% produced capsule, $49.4 \%$ produced fimbriae, $53.5 \%$ produced hemolysin and $20.2 \%$ showed proteolytic activity. Most of the isolated strains presented high levels of cellular hydrophobicity and the association between capsule production and adhesion to cotton cloth were statistically significant. The presence of potentially pathogenic bacteria as Escherichia coli, Staphylococcus aureus and Staphylococcus coagulase negative reveals the necessity of a microbiological control at milk production level, with the purpose to avoid major public health problems.

Key words: biofilms, milk, bacteria, virulence factors, hydrophobicity.

*Trabalho originado da Dissertação de Mestrado da primeira autora e financiado pela CAPES. ${ }^{1}$ Programa de Pós-graduação em Microbiologia Agrícola e do Ambiente (PPGMAA), Faculdade de Agronomia, Universidade Federal do Rio Grande do Sul (UFRGS), Porto Alegre, RS/Brasil. ${ }^{2}$ Acadêmica, Bolsista PROGRAD-UFRGS. ${ }^{3}$ Departamento de Microbiologia, Instituto de Ciências Básicas da Saúde (ICBS)/UFRGS.

CORRESPONDÊNCIA: J. Flach [juli_flach@yahoo.com.br ; Fax: + 5133164111 ]. 


\section{INTRODUÇÃO}

Biofilmes são agregados de microrganismos embebidos em uma matriz polimérica e aderidos a uma superfície sólida, formando uma estrutura porosa e altamente hidratada contendo exopolissacarídeos e pequenos canais, abertos por entre as microcolônias [10]. Este tipo de organização é extremamente vantajoso a todas as espécies de microrganismos, por fornecer proteção contra adversidades como desidratação, colonização por bacteriófagos e resistência a antimicrobianos [7].

Na linha de produção da indústria de laticínios, a formação de biofilmes eleva a carga microbiana e, muitas vezes, contamina com patógenos os alimentos que ali circulam, devido ao eventual desprendimento de porções aderidas. Dessa forma, podem colocar em risco a saúde do consumidor, além de ocasionar prejuízos financeiros à indústria, em virtude da diminuição da vida de prateleira dos produtos alimentícios [13, 23].

Existem vários fatores relacionados à formação de biofilmes. Os principais são: características físicoquímicas do material sobre o qual estão aderidos e expressão de fatores de virulência por parte dos microrganismos, como produção de cápsula exopolimérica, fímbrias e síntese de adesinas fímbrias e não fímbrias [24].

No presente estudo, buscou-se determinar a relação entre a produção de fatores de virulência relacionados à colonização de superfícies e à formação de biofilmes em diversos materiais de importância na indústria de laticínios. Avaliou-se também a atividade citotóxica e a atividade proteolítica dos isolados bacterianos, a última, relacionada à degradação do leite.

\section{MATERIAIS E MÉTODOS}

\section{Isolamento e identificação de bactérias do biofilme}

Três amostras de leite in natura foram aliquotadas em tubos estéreis contendo chapas retangulares (24mm x $12 \mathrm{~mm} \times 0,1 \mathrm{~mm})$ de aço inoxidável ${ }^{1}$, polipropileno $^{2}$ e pano de algodão ${ }^{3}$. Estes foram incubados nas temperaturas de $10^{\circ} \mathrm{C}$ e $25^{\circ} \mathrm{C}$. Após $2 \mathrm{~h}, 5 \mathrm{~h}$ e $8 \mathrm{~h}$ de incubação, as chapas foram retiradas e lavadas com solução PBS (Salina Fosfatada Tamponada) para a remoção de células não aderidas. Em seguida, as chapas foram colocadas em água peptonada estéril e submetidas a um banho de ultra-som $(\sim 40 \mathrm{mHz})$ por dois períodos de 10 minutos, para a remoção das células do biofilme. O líquido sonicado foi diluído serialmente e semeado em placas de ágar Eosina-Azul de Metileno $(\mathrm{EMB})^{4}$, ágar Baird-Parker ${ }^{5}$ e ágar Cereus ${ }^{6}$ não suplementado com Polimixina B. As placas de ágar
EMB e Baird-Parker foram incubadas a $37^{\circ} \mathrm{C}$, sendo o ágar Cereus incubado a $30^{\circ} \mathrm{C}$. Colônias típicas e não típicas foram isoladas dos meios, identificadas através de provas bioquímicas e estocadas em glicerol (15\%) a $-20^{\circ} \mathrm{C}[12,14]$.

\section{Teste para detecção da produção de cápsula}

Os isolados foram inoculados em caldo tripticaseína de soja $(\mathrm{TSB})^{7}$ e incubados a $37^{\circ} \mathrm{C}$ por 24 horas. Após, foi realizado o esfregaço, utilizando-se 2 gotas da suspensão bacteriana e 2 gotas de Vermelho Congo, o qual foi seco à temperatura ambiente e tratado com solução de Maneval por 1 minuto; o material foi observado em microscópio óptico 1000x, com óleo de imersão [18].

\section{Teste para detecção da produção de fímbria e fímbria tipo 1}

Os isolados foram cultivados em caldo TSB por $5-6 \mathrm{~h}$ a $37^{\circ} \mathrm{C}$, seguido de inoculação em ágar CFA e incubação por $24 \mathrm{~h}$ na mesma temperatura. Posteriormente, a cultura foi suspensa em solução PBS, com turbidez correspondente a $1,2 \times 10^{9}$ células $/ \mathrm{mL}$ (Mac Farland, tubo 4). Esta também foi determinada em fotocolorímetro microprocessado $^{8}$ (Analyser 500M), com D.O. em $620 \mathrm{~nm}$ equivalente a 0,59 .

No teste de produção de fímbria/adesinas, as suspensões foram diluídas em solução PBS, em microplacas, até a diluição 1:256 em um volume final de $50 \mathrm{~mL}$. A cada diluição foram adicionados $50 \mathrm{~mL}$ de suspensão de eritrócitos de carneiro a $1 \%$, e as microplacas incubadas a $4^{\circ} \mathrm{C}$ por $18 \mathrm{~h}$. A formação de halo de precipitação em cavidades com título superior a 1:4 foi considerada resultado positivo. O teste foi realizado em triplicata [21].

Para tipificação de fímbria tipo 1, foi utilizado o teste de Aglutinação de MOS (mananoligossacarídeo). Foram homogeneizados $100 \mu \mathrm{L}$ da suspensão de células bacterianas obtida acima e $100 \mathrm{~mL}$ de suspensão de MOS a 0,1\% em PBS. Após incubação por 30 minutos a $5^{\circ} \mathrm{C}$, foram aliquotados $20 \mathrm{~mL}$ do homogeneizado em lâmina de vidro, seguindo-se a observação em microscopia óptica (400x). Fímbrias do tipo 1 aglutinam ao MOS/PBS [6].

\section{Testes para detecção da produção de proteases e hemolisinas}

Culturas bacterianas foram inoculadas através de picada em placas de Ágar Sangue de Carneiro (5\%) e Ágar Leite, as quais foram incubadas a $37^{\circ} \mathrm{C}$ por $24 / 48$ horas. A presença de zonas circulares de hemólise ou degradação em volta das colônias bacterianas 
indicou resultado positivo para atividade hemolítica e proteolítica, respectivamente [4,5].

\section{Determinação da hidrofobicidade celular}

Após crescimento em ágar tripticaseína de soja $(\mathrm{TSA})^{8}$ por $18 \mathrm{~h}$ a $37^{\circ} \mathrm{C}$, as culturas foram suspensas em solução PBS e testadas para evidenciar isolados autoaglutinadores. Em caso de resultado negativo neste teste, os isolados foram então suspensos com concentrações crescentes de sulfato de amônio, de $0,5 \mathrm{M}, 1,0 \mathrm{M}$, $1,5 \mathrm{M}, 2,0 \mathrm{M}, 2,5 \mathrm{M}$ e $3,0 \mathrm{M}$. A formação de grumos em até dois minutos após a suspensão indica resultado positivo [17].

\section{Análise estatística}

Os resultados foram analisados estatisticamente através do teste $\chi^{2}$ complementado pela Análise de Resíduos Ajustados, Teste $t$ e Análise de Variância (ANOVA).

\section{Resultados}

Foram obtidos 101 isolados do biofilme (Tabela 1) e todos foram testados quanto à produção de fatores de virulência. Entre os Gram negativos $(n=57), 46$ pertencem à família Enterobacteriaceae e entre os Gram positivos, todos foram do gênero Staphylococcus.

Do total de isolados testados, $52,5 \%$ foram produtores de cápsula, $49,4 \%$ de fímbria, $4,0 \%$ de fímbria tipo I, $53,5 \%$ de hemolisina e $20,2 \%$ de proteases. A comparação quanto à produção de fimbrias/ adesina, cápsula, proteses e hemolisina, entre os isolados Gram negativos e Gram positivos, estão na Tabela 2. Entre os isolados da família Enterobacteriaceae, foram observados 4 produtores de fímbria tipo I, sendo dois isolados de aço inoxidável, um de pano de algodão e um de polipropileno.

A Tabela 3 refere-se à distribuição dos fatores de virulência cápsula e fímbrias/adesinas, entre isolados dos diversos materiais, além do resultado dos testes de hidrofobicidade para enterobactérias e estafilococos. Isolados não pertencentes a esses grupos não foram considerados nesta comparação.

Dos microrganismos Gram-positivos e Gramnegativos, $86,6 \%$ e $84,4 \%$ foram positivos para o teste de hidrofobicidade, respectivamente. Entre o primeiro grupo, 26,6\% foram aglutinantes em concentrações de sulfato de amônio iguais ou inferiores a $1 \mathrm{M}$. Enquanto que para os Gram-negativos, essa taxa foi de $34,4 \%$. Os Gram-positivos auto-aglutinantes representaram $8,8 \%$ do total de isolados desse grupo, e os Gramnegativos, $12,0 \%$.
A análise estatística demonstrou haver associação entre presença de cápsula e adesão no pano de algodão $(p<0,05)$, enquanto que o resultado oposto foi obtido para o polipropileno, em mesmo nível de significância. A presença de fímbria não foi significativamente associada aos materiais testados. Já, com relação à aglutinação em até $0,5 \mathrm{M}$ de sulfato de amônio, houve associação entre tipo de parede celular e hidrofobicidade em nível de significância de 0,05 , sendo os Gram-negativos mais hidrofóbicos do que os Grampositivos $(24,1 \%$ e $8,8 \%$, respectivamente).

\section{DISCUSSÃO}

A partir dos resultados mostrados, observa-se que as Gram-negativas, em sua maioria pertencentes à família Enterobacteriaceae, foram superiores na pro-

Tabela 1. Espécies bacterianas Gram positivas e Gram negativas isoladas de biofilmes formados a partir de amostras de leite em placas de aço inox, vidro, polipropileno e pedaços de pano de algodão.

\begin{tabular}{|c|c|}
\hline Gram-negativos $(n=57)$ & Número de isolados \\
\hline Cedecea sp. & 1 \\
\hline Comamonas sp. & 1 \\
\hline Enterobacter asburiae & 3 \\
\hline Enterobacter cloacae & 6 \\
\hline Enterobacter hormaechae & 2 \\
\hline Escherichia coli & 14 \\
\hline Hafnia alvei & 3 \\
\hline Kluyuera sp. & 2 \\
\hline Pseudomonas sp. & 1 \\
\hline Pseudomonas alcaligenes & 5 \\
\hline Serratia fonticola & 10 \\
\hline Serratia plymuthica & 5 \\
\hline Xanthomonas sp. & 4 \\
\hline \multicolumn{2}{|l|}{ Gram-positivos ( $n=44$ ) } \\
\hline Staphylococcus aureus & 13 \\
\hline Staphylococcus caprae & 6 \\
\hline Staphylococcus chromogens & 8 \\
\hline Staphylococcus intermedius & 11 \\
\hline Staphylococcus klosii & 1 \\
\hline Staphylococcus lentus & 2 \\
\hline Staphylococcus sciuri & 1 \\
\hline Staphylococcus warneri & 2 \\
\hline Total & 101 \\
\hline
\end{tabular}




\begin{tabular}{|c|c|c|c|c|c|}
\hline Grupo & $\begin{array}{c}\mathrm{N}^{\circ} \text { de } \\
\text { isolados }\end{array}$ & Cápsula & $\begin{array}{l}\text { Fímbria/ } \\
\text { adesinas }\end{array}$ & Proteases & Hemolisina \\
\hline Gram-negativos & 57 & $84,2 \%$ & $61,4 \%$ & $21,0 \%$ & $35,0 \%$ \\
\hline Gram-positivos & 44 & $9,0 \%$ & $34,1 \%$ & $19,0 \%$ & $78,5 \%$ \\
\hline
\end{tabular}

\begin{tabular}{|c|c|c|c|c|c|c|c|}
\hline \multirow[b]{3}{*}{ Material } & \multicolumn{3}{|c|}{ Enterobactérias $(n=46)$} & \multicolumn{4}{|c|}{ Estafilococos $(n=44)$} \\
\hline & \multicolumn{3}{|c|}{ Fatores de virulência } & \multirow[b]{2}{*}{ Material } & \multicolumn{3}{|c|}{ Fatores de virulência } \\
\hline & Cápsula & $\begin{array}{l}\text { Fímbria/ } \\
\text { adesinas }\end{array}$ & Hidrofobicidade & & Cápsula & $\begin{array}{l}\text { Fímbria/ } \\
\text { adesinas }\end{array}$ & Hidrofobicidade \\
\hline $\begin{array}{c}\text { Pano de } \\
\text { algodão } n=38\end{array}$ & $\begin{array}{c}32 / 38 \\
(84,2 \%)\end{array}$ & $\begin{array}{c}25 / 38 \\
(65,8 \%)\end{array}$ & $\begin{array}{c}33 / 38 \\
(86,8 \%)\end{array}$ & $\begin{array}{l}\text { Pano de } \\
\text { algodão } n=15\end{array}$ & $\begin{array}{c}2 / 15 \\
(13,3 \%)\end{array}$ & $\begin{array}{c}3 / 15 \\
(20,0 \%)\end{array}$ & $\begin{array}{c}12 / 15 \\
(80,0 \%)\end{array}$ \\
\hline $\begin{array}{c}\text { Polipropileno } \\
\text { n=2 }\end{array}$ & $\begin{array}{c}2 / 2 \\
(100 \%)\end{array}$ & $\begin{array}{c}1 / 2 \\
(50,0 \%)\end{array}$ & $\begin{array}{c}2 / 2 \\
(100 \%)\end{array}$ & $\begin{array}{c}\text { Polipropileno } \\
\mathrm{n}=17\end{array}$ & 0 & $\begin{array}{c}8 / 17 \\
(47,0 \%)\end{array}$ & $\begin{array}{c}16 / 17 \\
(94,1 \%)\end{array}$ \\
\hline $\begin{array}{c}\text { Aço inoxidável } \\
n=6\end{array}$ & $\begin{array}{c}5 / 6 \\
(83,3 \%) \\
\end{array}$ & $\begin{array}{c}6 / 6 \\
(100 \%) \\
\end{array}$ & $\begin{array}{c}6 / 6 \\
(100 \%) \\
\end{array}$ & $\begin{array}{c}\text { Aço inoxidável } \\
n=12\end{array}$ & $\begin{array}{c}2 / 12 \\
(17,0 \%) \\
\end{array}$ & $\begin{array}{c}3 / 12 \\
(25,0 \%) \\
\end{array}$ & $\begin{array}{c}8 / 12 \\
(67,0 \%) \\
\end{array}$ \\
\hline Total & $\begin{array}{c}39 \\
(84,7 \%)\end{array}$ & $\begin{array}{c}32 \\
(69,6 \%)\end{array}$ & $\begin{array}{c}41 \\
(89,1 \%)\end{array}$ & Total & $\begin{array}{c}4 \\
(9,0 \%)\end{array}$ & $\begin{array}{c}15 \\
(34,1 \%)\end{array}$ & $\begin{array}{c}36 \\
(81,8 \%)\end{array}$ \\
\hline
\end{tabular}

dução de cápsula e de fímbria em relação às Grampositivas, representadas pelo gênero Staphylococcus. Por outro lado, estes prevaleceram na produção de hemolisina. Quanto à produção de proteases, os dois grupos não apresentaram diferenças significativas.

Os membros da família Enterobacteriaceae utilizados nesse trabalho produziram uma maior quantidade de fatores de adesão e foram encontrados com maior incidência no pano de algodão. Todavia, sua adesão foi significantemente menor que a do gênero Staphylococcus ao polipropileno. Para explicar esse fato, sugere-se o envolvimento de outros fatores, como características físico-químicas da superfície, capazes de proporcionar filmes condicionantes de diferentes naturezas, provocando a atração das células bacterianas para próximo da superfície. Outros fatores seriam o número e o estado fisiológico das células no momento da análise [3,20]. Nesse caso, e baseados na interpretação estatística dos dados, pode-se sugerir que o filme condicionante formado no polipropileno não favoreceu a adesão de células produtoras de cápsula.

A associação entre cápsula e adesão em pano de algodão vem justificar o maior número de isolados da família Enterobacteriaceae nele encontrados. Por ser um material poroso e com fendas, proporciona abrigo aos microrganismos, fazendo com que estes levem menos tempo para iniciar ou persistir na síntese de exopolissacarídeos, ingressando na fase irreversível de adesão. Como os Staphylococcus não produzem essa estrutura com tanta frequiência, poderiam ser mais facilmente removidos das fendas do pano de algodão com a lavagem.

Embora influenciada pela produção de exopolissacarídeos e proteínas de superfície, a hidrofobicidade entre os grupos, não apresentou diferença significativa. Esta observação sugere que existam outros fatores determinando essa característica, como o tipo de exopolissacarídeos produzidos e até mesmo a composição do meio de cultura utilizado no teste da hidrofobicidade [8,9,11]. Apesar de não ter sido esperado, este resultado é condizente com a literatura, ao corroborar a hipótese de que a hidrofobicidade celular é importante na adesão aos materiais testados, já que ambos os grupos foram capazes de aderir e apresentaram altas taxas de positividade para o teste. Entretanto, a atuação de outros componentes da superfície bacteriana, e não só a hidrofobicidade, deve ser considerada neste processo, embora a adesão celular mediada por interações hidrofóbicas nem sempre tenha grande relevância $[9,19]$. 
A diversidade bacteriana encontrada no presente trabalho vem ao encontro de observações realizadas em outros trabalhos, que apontam os gêneros Pseudomonas, Alcaligenes, Enterobacter, Staphylococcus, Bacillus, Flavobacterium e Escherichia como os que apresentam uma maior tendência em formar biofilmes [15,16].

Cabe aqui ressaltar também o isolamento de microrganismos tradicionalmente patógenos, como Escherichia coli e Staphylococcus aureus, além de patógenos emergentes, pertencentes ao grupo dos Staphylococcus coagulase-negativos, como Staphylococcus caprae. Embora mais associado a patogenia em caprinos, existem trabalhos relatando a presença deste último na microbiota humana, sendo, inclusive, responsável por infecções em pacientes com implantes cirúrgicos $[1,2,22]$. Nesse caso, sugere-se que este microrganismo tenha advindo dos manipuladores ou utensílios contaminados.

A presença desses grupos de microrganismos organizadas em biofilmes no leite in natura representam um risco à saúde do consumidor e geram preocupação. Na ausência de um processo de sanificação adequado, os possíveis patógenos formarão biofilmes na indústria e poderão vir a contaminar e/ou diminuir a vida de prateleira dos alimentos, uma vez que muitos foram também produtores de proteases.

\section{CONCLUSÕES}

Os resultados do presente trabalho mostram haver relação direta entre formação de biofilmes e produção de fatores de virulência relacionados à adesão, pelos microrganismos, principalmente com relação à produção de cápsula e hidrofobicidade celular. Entretanto, como a formação de biofilmes é um processo multifatorial, é necessário considerar também a influência de outras características, pertinentes ou não à célula bacteriana e que merecem estudos mais aprofundados.

$\mathrm{O}$ isolamento, no leite in natura, de microrganismos capazes de sintetizar enzimas com atividade citotóxica ou proteolítica enfatiza a importância do controle microbiológico já em nível de propriedade rural, reduzindo a carga microbiana que ingressa na indústria de beneficiamento e assegurando um produto de melhor qualidade ao consumidor.

Agradecimentos. Agradecemos à Claudete Inês Locatelli, do Hospital de Clínicas de Porto Alegre (HCPA) pela valiosa contribuição nas análises de hidrofobicidade celular, à Sérgio Katto, do Núcleo de Assessoria Estatística (NAE-UFRGS) pela execução das análises estatísticas e aos Órgãos de Fomento CAPES/PROF e PROGRAD/UFRGS.

\section{NOTAS INFORMATIVAS}

${ }^{1}$ AISI 410, Sulinox, Porto Alegre, Brasil.

${ }^{2}$ Bioplast, Porto Alegre, Brasil.

${ }^{3}$ Sober S.A., Porto Alegre, Brasil.

${ }^{4}$ Merck S.A., Damstadt, Germany.

${ }^{5}$ Laboratótios Difco, Sparks, USA.

${ }^{6}$ Merck S.A., Damstadt, Germany.

${ }^{7}$ HiMedia Laboratories Pvt Ltd., Mumbai, Índia.

${ }^{8}$ Analyser 500M, São Paulo, Brasil

${ }^{9}$ HiMedia Laboratories Pvt Ltd., Mumbai, Índia.

\section{REFERÊNCIAS}

1 Allignet J., Aubert S., Dyke K.G.H. \& Solh N.E. 2001. Staphylococcus caprae strains carry determinants known to be involved in pathogenicity: a gene encoding an autolysin-binding fibronectin and the ica operon involved in biofilm formation. Infection and immunity. 69 (Suppl 2): 712-718.

2 Allignet J., Galdbart J.O., Morvan A., Dyke K.G.H., Vaudaux P., Desplaces S.A.N. \& Solh N.E. 1999. Tracking adhesion factors in Staphylococcus caprae strains responsible for human bone infections following implantation of orthopaedic material. Microbiology. 145: 2033-2042.

3 Boulange-Petermann L. 1996. Processes of bioadhesion on stainless steel surfaces and cleanability: a review with special reference to the foodindustry. Biofouling. 10: 275-300.

4 Budi S.W., Tuinen D.V., Arnould C., Gaudot E.D., Pearson V.G. \& Gianinazzi S. 2000. Hydrolytic enzyme activity of Paenibacillus sp. Strain B2 and effects of the antagonistic bacterium on cell integrity of two soil-borne pathogenic fungi. Applied Soil Ecology. 15:191-199.

5 Dias A.M.G., Kano E., Nakahara L.K., Fernandes S.L., Kato M.A.M.F. \& Irino K. 1994. Virulence factors in Escherichia coli isolated from blood and cerebrospinal fluid. Reviews of Microbiology. 25 (Suppl 2): 77-82.

6 Finucane M., Spring P. \& Newman K. 1999. Incidence of mannose sensitive adhesions in enteric bacteria. Poultry Science. 78 (Suppl 1): 139.

7 Gilbert P., McBain A.J. \& Rickard A.H. 2003. Formation of microbial biofilm in hygienic situations: a problem of control. International Biodeterioration \& Biodegradation. 51: 245-248. 
8 Gross M.J. \& Logan B.E. 1995. Influence of different chemical treatments on transport of Alcaligenes paradoxus in porous media. Applied Environmental Microbiology. 61:1750-1756.

9 Hassan A.N. \& Frank J.F. 2004. Attachment of Escherichia coli O157:H7 grown in tryptic soy broth and nutrient broth to apple and lettuce surfaces as related to cell. hydrophobicity, surface charge, and capsule production. International Journal of Food Microbiology. 96:103-109.

10 Lawrence J.R., Korber D.R., Hoyle B.D., Costerton J.W. \& Caldwell D.E. 1991. Optical sectioning of microbial biofilms. Journal of Bacteriology. 173: 6558-6567.

11 Ljungh A., Hjerten S. \& Wadstrom T. 1985. High Surface Hydrophobicity of Autoaggregating Staphylococcus aureus Strains Isolated from Human Infections Studied with the Salt Aggregation Test. Infection and immunity. 47 (Suppl 2): $522-526$.

12 MacFaddin J.F. 2000. Biochemical Test for Identification of Medical Bacteria. 3rd edn. Baltimore: Williams\& Wilkins, 912p.

13 Marshall K.C. 1992. Biofilms: an overview of bacterial adhesion, activity and control at surfaces. American Society of Microbiology. 58: 202-207.

14 Murray R.G.E., Brenner D.J., Bryant M.P., Holt J.G., Krieg N.R., Moulder J.W., Pfennig N., Sneath P.H.A. \& Staley J.T. 1984. Bergey's Manual of Systematic Bacteriology. Baltimore: Williams \& Wilkins, 1599p.

15 Pompermayer D. \& Gaylarde M.C. 2000. The influence of temperature on the adhesion of mixed cultures of Staphylococcus aureus and Escherichia coli to polypropylene. Food Microbiology. 17: 361-365.

16 Poulsen L.V. 1999. Microbial Biofilm in Food Processing. Lebensmittel-Wissenschaft und-Technologie. 32 (Suppl 6): $321-326$.

17 Schmidt H., Schlöricke E., Fislage R., Schulze H. \& Guthoff R. 1998. Effect of surface modifications of intraocular lenses on the adherence of Staphylococcus epidermidis. Zentralblatt für Bakteriologie. 287 (Suppl 1): 135-145.

18 Seeley J.R., Vandemark H.W. \& Lee J.J. 1991. Structural Stains. In: Microbes in action: a laboratory manual of microbiology. New York: H. W. Freeman and Company, pp.87-89.

19 Sinde E. \& Carballo J. 2000. Attachment of Salmonella spp. and Listeria monocytogenes to stainless steel, rubber and polytetrafluorethylene: the influence of free energy and the effect of commercial sanitizers. Food Microbiology. 17: $439-447$.

20 Stone L.S. \& Zottola E.A. 1985. Relationship between the growth phase of Pseudomonas fragi and its attachment to stainless steel. Journal of Food Science. 50: 957-960.

21 Truszczynsky M. \& Osek J. 1987. Occurrence of mannose resistant hemaglutinins in Escherichia coli strains isolated from porcine Colibacillosis. Immunology and Microbiology Infections Disease. 10: 117-124.

22 Vandenesch F., Eykyn S.J., Bes M., Meugnier H., Fleurette J. \& Etienne J. 1995. Identification and ribotypes of Staphylococcus caprae isolates isolated as human pathogens and from goat milk. Journal of Clinical Microbiology. 33: 888-892.

23 Zottola E.A. 1994. Microbial attachment and biofilm formation: A new problem for the food industry?. Food Technology. 48: $107-114$.

24 Zottola E.A. \& Sasahara K.C. 1994. Microbial biofilms in the food processing industry - Should they be a concern? International Journal of Food Microbiology. 23: 125-148. 